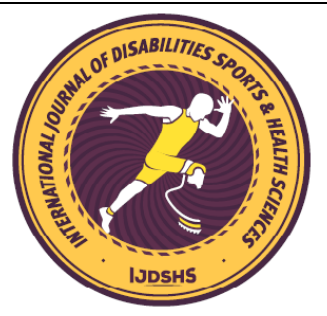

\title{
Is Nationality A Factor Affecting Serve Type, Serve Speed and Success In Professional Volleyball League?
}

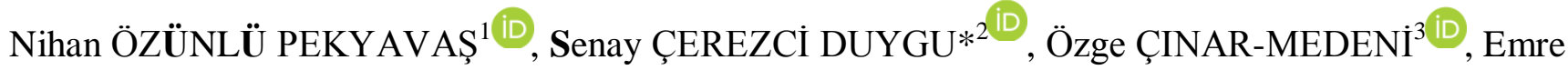

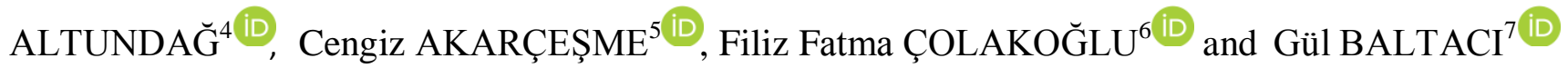

${ }^{1, * 2}$ Baskent University, Faculty of Health Sciences, Department of Physiotherapy and Rehabilitation, Baglica, Ankara, Turkey

${ }^{3}$ Cankırı Karatekin University, School of Health, Department of Physiotherapy and Rehabilitation, Cankırı, Turkey

${ }^{4,5,6}$ Gazi University, School of Physical Education and Sport, Ankara, Turkey

${ }^{7}$ Guven Private Hospitals, Physiotherapy and Rehabilitation Center, Kavaklidere, Ankara, Turkey

*Corresponding author: senaycerezci@gmail.com

\begin{abstract}
In professional volleyball, serving is one of the most important attacking options. A strong and qualified service is important to be successful in the game. There is limited research about comparison of native and foreign volleyball players and also no research was found about Turkish players. The aim of our study was to determine if being a national or a foreign player affects serve speed, serve type and success. Total of 6168 serve shots were included in our study. Four groups were determined as native woman players $(n=1836)$, foreign woman players $(n=1036)$, native man players $(n=1886)$ and foreign man players $(n=1410)$ serve shots. Serve speeds were measured by using Radar Gun (Pocket Radar, Santa Rosa, CA, USA). Serve types and serve efficiencies were recorded during game. There was significant difference between the groups in terms of serve speeds $(F=1012.618 p \leq 0.01)$. Also statistically significant difference was found bet ween four groups for serve types ( $\leq \leq 0.01)$ and serve efficiencies $(\mathrm{p}=0.028)$. Our results might be a result of training type used from the beginning of sports life of the volleyball player. When we consider the findings, we think that the speed, type and effectiveness of serves should be evaluated and followed for training and tactical development.
\end{abstract}

\section{Keywords}

Sports; Volleyball; Match analysis; Serve analysis

\section{INTRODUCTION}

Volleyball is a complex sport demanding technical, tactical and athletic performances of the player (Moras et al., 2008). To provide success in these performances, authors stated that efficient components of volleyball success are related to technical service characteristics (type of service and service speed) (Quiroga et al., 2012), height of contact, ball direction, ball speed (Palao \& Valades, 2009), team category, points obtained in the break point phase, number of reception errors, and number of blocked attacks by the opponent (Peña, Rodríguez-Guerra, Buscà, \& Serra, 2013).

In professional volleyball, serving is one of the most important attacking options. A strong and qualified service is important to be successful in the game. With the improvement in serve effectiveness, player can limit or avoid the opponent teams attacking options and therefore contribute defense (Fernandez-Echeverria, Gil, Moreno, Claver, \& Moreno, 2015; García-deAlcaraz, Ortega, \& Palao, 2016). 
The different kinds of serve are categorized and named according to the ball movement after being hit (i.e., floating or with rotation) and whether or not the server is touching the ground (i.e., standing or jumping) (García-de-Alcaraz et al., 2016) . With all this in mind, the serve can be classified as Jump Topspin, Jump Float and Tennis (Jiménez-Olmedo, Penichet-Tomás, SáizColomina, Martínez-Carbonell, \& Jove-Tossi, 2012; Moras et al., 2008). Although jump serve has a higher failure percentage than other service styles, all high-level teams seem to accept the high risk of error related to this style. When past studies are examined, it was reported that one of the 5 jump serve is net or out of play whereas the rate for other services is approximately 1 in 12 (Moras et al., 2008). Given this situation, it's not fully true to examine the effect of jump serve only according to the ace points or the serves which opponent can't receive easily. Here, rather than the direct successes brought, the conditions that impede should be evaluated. As mentioned in previous studies, in a high-level volleyball attack is a stronger predictor than defense for the success of the team (Moras et al., 2008). Given all this, Jump Serve is the most powerful technique in terms of increasing defensive difficulties but, at the same time, it has high percentage of errors (Ciuffarella et al., 2013).

There is limited research about comparison of native and foreign volleyball players and also no research was found about Turkish players. Therefore the aim of our study was to determine if being a national or a foreign player affects serve type, serve speed and success during one season in Elite Men's and Women's Volleyball-League.

\section{MATERIALS AND METHODS}

Ethical approval for this study was obtained from Başkent University Non-interventional Clinical Researches Ethics Board (KA20/398). Written informed consent was obtained from all subjects before the study.

\subsection{Subjects \& Groups}

Total of 6168 serve shots were included in our study. Four groups were determined as native woman players serve shots $(\mathrm{n}=1836$ shot $)$, foreign woman players serve shots $(\mathrm{n}=1036$ shot), native man players serve shots $(\mathrm{n}=1886$ shot $)$ and foreign man players serve shots $(n=1410$ shot $)$. All evaluations were taken during the 2016-2017
Volleyball Eagle League and Sultan's Volleyball League Seasons.

\subsection{Serve Speed}

Two experts (sports trainers) have observed recorded data during competition. Tests were performed by the same examiner on all athletes to avoid inter-tester inconsistencies. A radar gun (Pocket Radar, Santa Rosa, CA, USA) was used to simultaneously measure ball velocity from behind the strike zone. Serve speed was recorded as miles per hour (MPH). The radar records the speed of an object by the emission and reception of radio waves (Palao \& Valades, 2009). The radar was positioned on the platform placed for statistical trainees at the back of the field, at a distance of 5 $\mathrm{m}$ from the service line, $1.5 \mathrm{~m}$ above the ground. The radar direction is reversed according to the service area (Moras et al., 2008; Tocci et al., 2017).

\subsection{Serve Type \& Serve Efficiency}

The second observer had recorded serve type and serve efficiency.

Serve types were recorded as Jump Topspin, Jump Float and Tennis. In JUMP TOP SPIN, player starts behind the line, throws the ball up and forward. At the same time runs forward and jumps at the end line, meets the ball in the air and executes a spike. In JUMP FLOAT, player starts behind the line, throws the ball up and forward. At the same time runs forward and jumps at the end line, meets the ball in the air, hits the ball hard to stop the spin of ball. Keeping the ball from spinning creates a float effect. In TENNIS, player stands little behind from end line or at the end line, than throws the ball up and hits the ball (A. Katsikadelli, 1996; Moras et al., 2008).

Serve efficiencies were divided in 4 categories: 1) Ace= direct point from that serve 2) Error $=$ outside 3) Positive $=$ successful, the opponent can't receive easily 4) Negative $=$ poor, the opponent receives easily. Serve success was recorded as win or lost.

\subsection{Statistical Analysis}

Statistical analysis was performed with the IBM SPSS Statistics V22 software. The mean and standard deviation of the data are represented. $\alpha$ value of 0.05 was taken to indicate statistical significance. Kolmogorov-Smirnov/Shapiro Wilk tests were done to assess the homogeneity of four groups. Comparisons between serve speeds of four groups were analyzed with ANOVA. Serve types, serve efficiencies and results of four groups were 
specified as percentiles (\%). Chi-Square Test was used to analyze differences between four groups in serve types, serve efficiencies and results.

\section{RESULTS}

Native man, foreign man, native woman and foreign woman serve shot groups were included in multiple comparisons which were statistically homogeneous.

There was significant difference between the groups in terms of serve speed $(\mathrm{F}=1012.618$ $\mathrm{p} \leq 0.01)$. In binary comparison of groups, a significant difference was found between native and foreign man players $(p<0.001)$ when there was no significant difference between native and foreign woman players $(p=0.355)$. Difference of man players are in favor of foreign players (Native $42.79 \pm 11.06$, Foreign 54.95 $\pm 14.02 \mathrm{MPH}$ ). Number of players in each group and Mean \pm Standart Deviation values of serve speeds were given in Chart 1. According to the Chi-Square Test, statistically significant difference was found between four groups for serve type $(p \leq 0.01)$ and serve efficiencies $(\mathrm{p}=0.028)$.

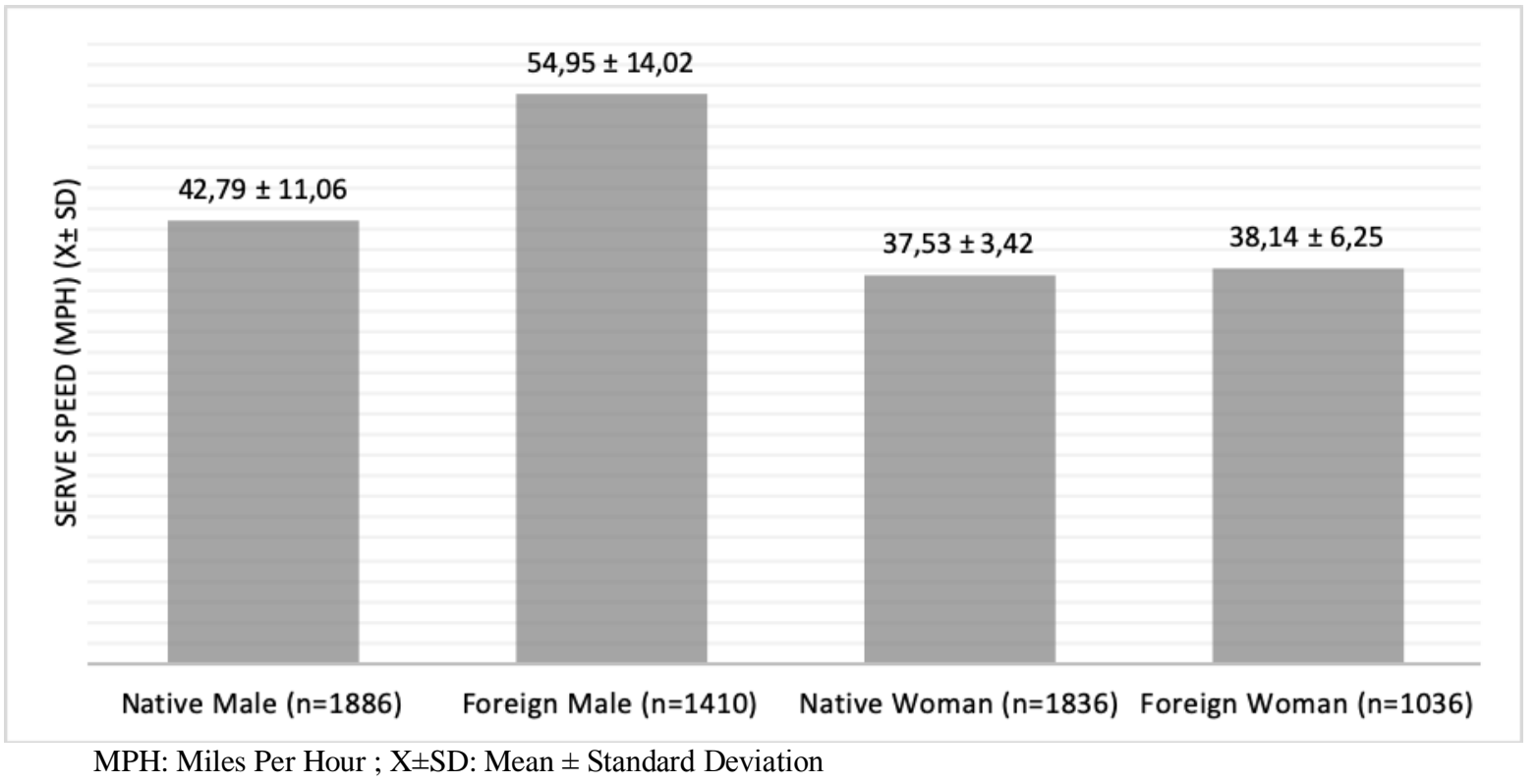

Chart 1. Serve speeds of each group

Percentiles of serve types are shown in Table $\mathbf{1}$ and serve efficiencies are shown in Chart 2a, Chart 2b.

Table 1. Nationality - Serve Type Frequencies

\begin{tabular}{|c|c|c|c|c|c|c|}
\hline \multirow{9}{*}{ Nationality } & \multirow{4}{*}{ Native man } & \multirow{4}{*}{$\begin{array}{l}\text { Count } \\
\% \text { within Nationality }\end{array}$} & \multicolumn{3}{|c|}{ Serve Type } & \multirow[b]{2}{*}{ Total } \\
\hline & & & $\begin{array}{c}\text { Jump } \\
\text { Topspin }\end{array}$ & Jump Float & Tennis & \\
\hline & & & 527 & 1354 & 5 & 1886 \\
\hline & & & $27,9 \%$ & $71,8 \%$ & ,3\% & $100,0 \%$ \\
\hline & Foreign man & Count & 1019 & 391 & $\mathbf{0}$ & 1410 \\
\hline & & $\%$ within Nationality & $72,3 \%$ & $27,7 \%$ &, $0 \%$ & $100,0 \%$ \\
\hline & Native woman & Count & 29 & 1586 & 221 & 1836 \\
\hline & & $\%$ within Nationality & $1,6 \%$ & $86,4 \%$ & $12,0 \%$ & $100,0 \%$ \\
\hline & Foreign woman & Count & 134 & 577 & 325 & 1036 \\
\hline & & $\%$ within Nationality & $12,9 \%$ & $55,7 \%$ & $31,4 \%$ & $100,0 \%$ \\
\hline Total & & Count & 1709 & 3908 & 551 & 6168 \\
\hline & & $\%$ within Nationality & $27,7 \%$ & $63,4 \%$ & $8,9 \%$ & $100,0 \%$ \\
\hline
\end{tabular}




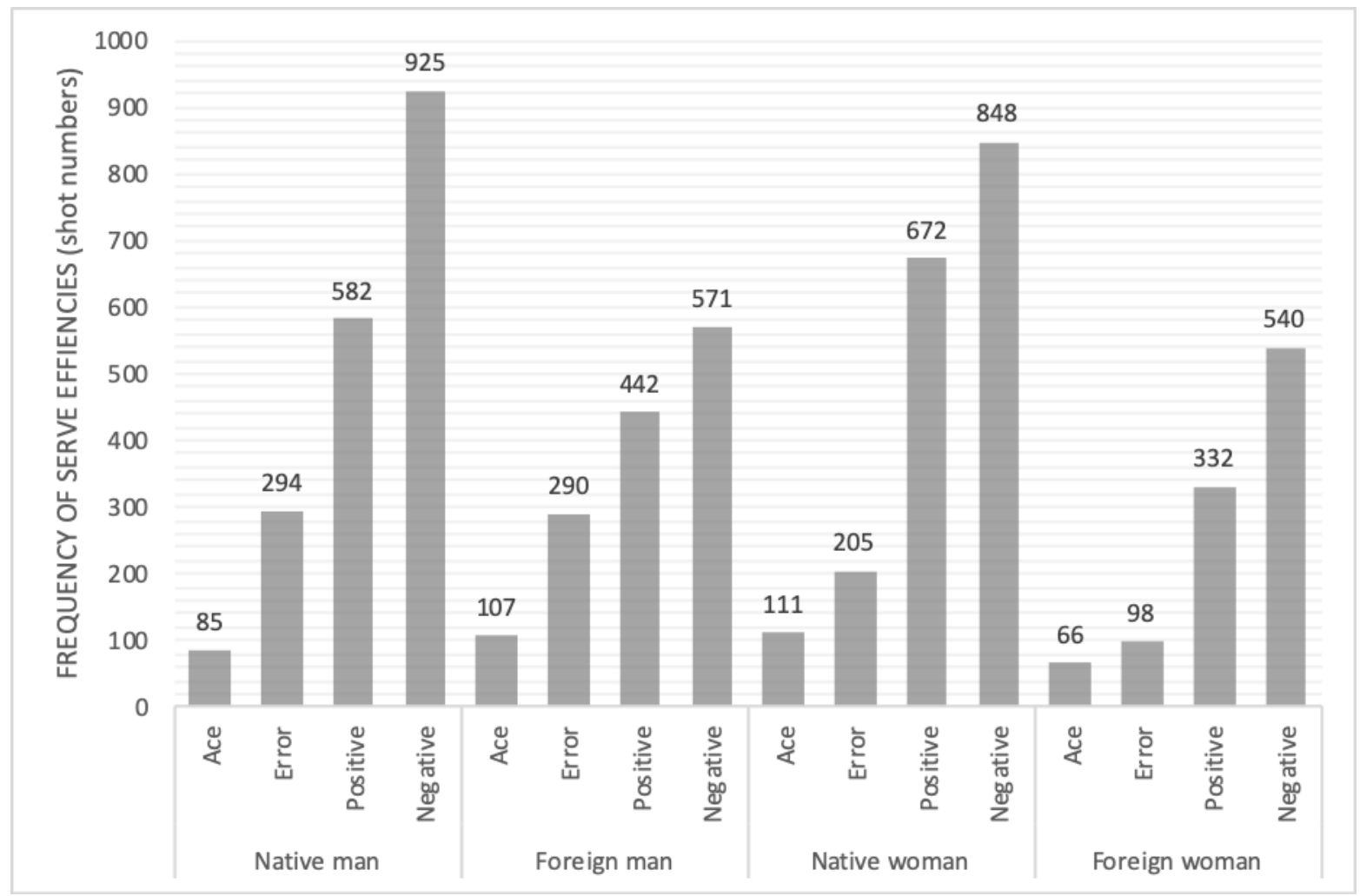

Chart 2a. Frequency of serve efficiencies

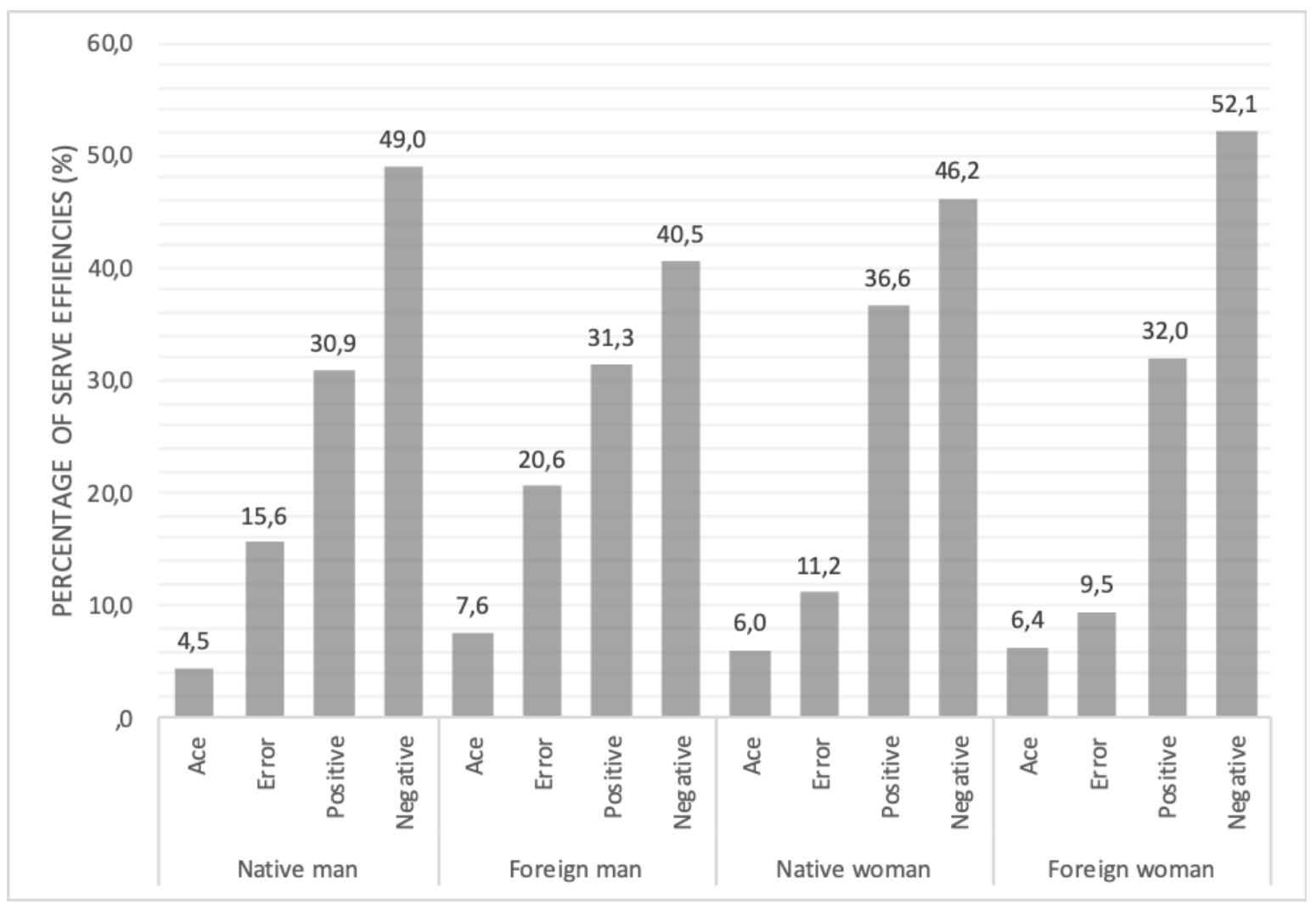

Chart 2b. Percentage of serve efficiencies 


\section{DISCUSSION}

This study aimed to determine if nationality and gender of the player affects serves type, serve speed, serve efficiency and result of the point during a season in Professional Volleyball League. It is found that serve speed of foreign men are better than Turkish men volleyball players but in women players there is no difference in terms of serve speed. We also found that serve type is different in man players; as foreign players mostly use Jump Topspin serve type and Turkish players mostly use Jump Float serve type. In women players, most frequent serve type is Jump Float (Native $86.4 \%$; Foreign 55.7\%). Native women players mostly use Tennis serve $(12.0 \%)$ whereas Foreign women mostly use Jump Topspin serve $(27.7 \%)$. However, we found that the serve efficiency and success of the players does not change at all.

Radar gun is found as a reliable assessment tool for measuring serve speed (Kolman, Huijgen, Kramer, Elferink-Gemser, \& Visscher, 2017). Technological improvement has permitted the radar to be used in sport research and training to monitor spike speed instead of using photogrammetry (Melrose, Spaniol, Bohling, \& Bonnette, 2007). We measured the serve speed with radar gun during the game in order to see the real efficiency of the player in the game. Considering serve speeds of elite male volleyball players ( $\mathrm{n}=3296$ serves) during the game, we saw that Turkish players have a mean of $42.79 \mathrm{MPH}$ while foreign players have a mean of $54.95 \mathrm{MPH}$ as serve speed. Therefore, as comparing the mean serve speeds of Native and Foreign volleyball players, we may say that Foreign players have higher serve speed than Native players. The reasons of this situation might be affected by many factors such as volleyball players' jump capacity or body mass index. Especially strength performance of the dominant shoulder (internal rotators) in volleyball players is found to be a main factor affecting serve speed (Forthomme, Croisier, Ciccarone, Crielaard, \& Cloes, 2005).

A study of Quiroga et al. showed that the most efficient component of volleyball success was related to technical service characteristics (type of service and service speed) (Quiroga et al., 2012). Three types of serve are defined used during the game: Jump Topspin, Jump Float and
Tennis (Jiménez-Olmedo et al., 2012; Moras et al., 2008). In our study, serve type is also found different in Foreign and Native man but not in woman players. As a result of our study, it is determined that Foreign man players use mostly Jump Topspin serve type whereas Native man players use mostly Jump Float serve type. Native and foreign woman players use mostly Jump Float serve. In different study Ciuffarella et al, confirmed that in Italian volleyball male Top League, there is the largest use of the Jump Top Spin $(69.9 \%)$, followed by the Jump Float (26.9\%) and the Tennis Serve $(3.3 \%)$. Our results might be a result of training type used from the beginning of sports life of the volleyball player. Also another reason might be that Jump Float which Native volleyball players mostly use is a more targeted and guaranteed serve type than Jump Topspin which seems more risky because it is not targeted. As some authors have noted, what is important is that the player feels physically and psychologically comfortable with the type of serve he uses, that brings the success (Afonso, Esteves, Araújo, Thomas, \& Mesquita, 2012; Macquet, 2009).

Beside a point which is immediately scored, the serve is also important for the later development of the game. Thereby, it has been reported that with an effective serve, reception performance (Quiroga et al., 2010, 2012) and the attacking options of the opposite team are affected and with this effect, first tempo attacks can be reduced and second tempo attacks can be increased (A. Katsikadelli, 1996; Papadimitriou, Pashali, Sermaki, Mellas, \& Papas, 2004). This effect of the serve on the attack performance can cause an increase in blocking options (FernandezEcheverria et al., 2015). Also Ciuffarella et al, investigated the effectiveness of serve types and refers to the necessity of using different types of services in different parts of the game (Ciuffarella et al., 2013). Thus in Professional volleyball it is highly important to start with effective serve which can limit opponents attact options and helps for defence. In our study according to the serve efficiency (ace, error, positive, negative) percentages are almost equal in all groups. $46.8 \%$ of all serves are categorised as 'negative'. This results suggests that we need to change service effectiveness to 'positive' when we are thinking about training and tactical development. 
As considering all of these results, the success of the serve is found similar in both Foreign and Native volleyball players. Many authors have pointed out that there are many factors affecting the success of the serve. Palao et al. stated that the success of the action depends on height of contact, ball direction, and ball speed (Palao \& Valades, 2009). Also Pena et al. stated that team category, points obtained in the break point phase, number of reception errors, and number of blocked attacks by the opponent were significant predictors of winning or losing the matches (Peña et al., 2013). The parameters measured in our study indicated that although serve speeds of Foreign players are higher and two groups use different serve types, the success of the serve might be similar for Native and Foreign players. This might lead us to the result of recruiting more Native players to national teams will bring the same success with recruiting foreign players.

\section{Limitations and Recommendations}

Even if we included many players to our study, the number of loyal players may be increased and may be compared again. The same measurements may be measured for specific teams and evaluated before and after the training season. Also to look at from another perception, the reason for the difference in service rates and the difference in service types may be explored more detailed (eg internal rotator force). It was not known whether body mass index, jumping heights and especially upper extremity muscle strength, which affect service speed, were similar in native and foreign players. This can be seen as a limitation and in future studies, the personal and physical characteristics of the players can be examined in more detail. Also, more studies should be done to evaluate technical serve characteristics, the effects on the development of the game and its consequences.

\section{CONCLUSION}

It is known and accepted that the most efficient component of volleyball success was related to technical serve characteristics. In our study, we shown that serve speed, type and efficiency characteristics are different in group due to the race and gender. In previous sections, we mentioned about their possible reasons of this situation. Regular monitoring of technical service features, the effects on the game's development and results are essential for success.

\section{REFERENCES}

A. Katsikadelli. (1996). A comparative study of the attack serve in high-level volleyball tournaments. Journal of Human Movement Studies, 30(6), 259-268. Retrieved from https://www.researchgate.net/publication/29 3527861_A_comparative_study_of_the_atta ck_serve_in_highlevel_volleyball_tournaments

Afonso, J., Esteves, F., Araújo, R., Thomas, L., \& Mesquita, I. (2012). Tactical determinants of setting zone in elite men's volleyball. Journal of Sports Science and Medicine, 11(1), 64-70.

Ciuffarella, A., Russo, L., Masedu, F., Valenti, M., Izzo, R. E., \& De Angelis, M. (2013). Notational Analysis of the Volleyball Serve. Timisoara Physical Education and Rehabilitation Journal, 6(11), 29-35. https://doi.org/10.2478/tperj-2013-0013

Fernandez-Echeverria, C., Gil, A., Moreno, A., Claver, F., \& Moreno, M. P. (2015). Analysis of the variables that predict serve efficacy in young volleyball players. International Journal of Performance Analysis in Sport, 15(1), 172-186. Retrieved from

https://www.tandfonline.com/doi/pdf/10.108 0/24748668.2015.11868785? needAccess $=$ tru e

Forthomme, B., Croisier, J.-L., Ciccarone, G., Crielaard, J.-M., \& Cloes, M. (2005). Factors Correlated with Volleyball Spike Velocity. The American Journal of Sports Medicine, 33(10), 1513-1519. https://doi.org/10.1177/0363546505274935

García-de-Alcaraz, A., Ortega, E., \& Palao, J. M. (2016). Effect of Age Group on TechnicalTactical Performance Profile of the Serve in Men's Volleyball. Perceptual and Motor Skills, 123(2), 508-525. https://doi.org/10.1177/0031512516660733

Jiménez-Olmedo, J. M., Penichet-Tomás, A., SáizColomina, S., Martínez-Carbonell, J. A., \& Jove-Tossi, M. A. (2012). Serve analysis of professional players in beach volleyball. Journal of Human Sport and Exercise, 7(3), 706-713. https://doi.org/10.4100/jhse.2012.73.10 
Kolman, N., Huijgen, B., Kramer, T., ElferinkGemser, M., \& Visscher, C. (2017). The Dutch Technical-Tactical Tennis Test (D4T) for Talent Identification and Development: Psychometric Characteristics. Journal of Human Kinetics, 55, 127-138. https://doi.org/10.1515/hukin-2017-0012

Macquet, A. C. (2009). Recognition Within the Decision-Making Process: A Case Study of Expert Volleyball Players. Journal of Applied Sport Psychology, 21(1), 64-79. https://doi.org/10.1080/10413200802575759

Melrose, D. R., Spaniol, F. J., Bohling, M. E., \& Bonnette, R. A. (2007). Physiological and Performance Characteristics of Adolescent Club Volleyball Players. The Journal of Strength and Conditioning Research, 21(2), 481. https://doi.org/10.1519/R-19185.1

Moras, G., Buscà, B., Peña, J., Rodríguez, S., Vallejo, L., Tous-Fajardo, J., \& Mujika, I. (2008). A comparative study between serve mode and speed and its effectiveness in a high-level volleyball tournament. Journal of Sports Medicine and Physical Fitness, 48(1), 31-36.

https://doi.org/10.1002/14651858.CD005954 .pub2.Fundings.

Palao, J. M., \& Valades, D. (2009). Testing protocol for monitoring spike and serve speed in volleyball. Strength and Conditioning Journal, 31(6), 47-51. https://doi.org/10.1519/SSC.0b013e3181c21 b3f

Papadimitriou, K., Pashali, E., Sermaki, I., Mellas, S., \& Papas, M. (2004). The effect of the opponents' serve on the offensive actions of Greek setters in volleyball games. International Journal of Performance Analysis in Sport, 4(1), 23-33. https://doi.org/10.1080/24748668.2004.1186 8288

Peña, J., Rodríguez-Guerra, J., Buscà, B., \& Serra, N. (2013). Which Skills and Factors Better Predict Winning and Losing in High-Level Men's Volleyball? Journal of Strength and Conditioning Research, 27(9), 2487-2493. https://doi.org/10.1519/JSC.0b013e31827f4dbe
Quiroga, M. E., García-Manso, J. M., RodríguezRuiz, D., Sarmiento, S., De Saa, Y., \& Moreno, M. P. (2010). Relation between InGame Role and Service Characteristics in Elite Women's Volleyball. Journal of Strength and Conditioning Research, 24(9), 2316-2321.

https://doi.org/10.1519/JSC.0b013e3181e38 $12 \mathrm{e}$

Quiroga, M. E., Rodriguez-Ruiz, D., Sarmiento, S., Muchaga, L. F., Da Silva Grigoletto, M., \& García-Manso, J. M. (2012). Characterisation of the Main Playing Variables Affecting the Service in HighLevel Women's Volleyball. Journal of Quantitative Analysis in Sports, 8(1), 1-13. https://doi.org/10.1515/1559-0410.1348

Tocci, N. X., Howell, D. R., Sugimoto, D., Dawkins, C., Whited, A., \& Bae, D. (2017). The Effect of Stride Length and Lateral Pelvic Tilt on Elbow Torque in Youth Baseball Pitchers. Journal of Applied Biomechanics, 33(5), 339-346. https://doi.org/10.1123/ijspp.2015-0012.

How to cite this article: Özünlü Pekyavaş, M., Çerezci Duygu, S., Çınar-Medeni, Ö., Altundağ, E., Akarçeşme, C., Çolakoğlu, F.F. and Baltac1, G. (2021). Is Nationality A Factor Affecting Serve Type, Serve Speed and Success In Professional Volleyball League?. Int J Disabil Sports Health Sci;4(1):58-60. https://doi.org/10.33438/ijdshs. 783018 